\title{
Colaboração em Ambientes Virtuais de Aprendizagem: uma proposta de contribuição ao processo de ensino e aprendizagem em Biologia
}

Collaboration in Virtual Learning Environments: a proposal to contribute to the teaching and learning process in Biology

Colaboración en Entornos Virtuales de Aprendizaje: una propuesta para contribuir al proceso de enseñanza y aprendizaje en Biología

Recebido: 10/09/2021 | Revisado: 15/09/2021 | Aceito: 22/09/2021 | Publicado: 24/09/2021

\author{
Alexandre Horácio Couto Bittencourt \\ ORCID: https://orcid.org/0000-0002-3838-1609 \\ Centro Universitário FAMINAS, Brasil \\ E-mail: alexandre.couto@unifaminas.edu.br \\ Nilson Sérgio Peres Sthal \\ ORCID: https://orcid.org/0000-0002-1949-0850 \\ Universidade Estadual do Norte Fluminense, Brasil \\ E-mail: nilson8080@gmail.com
}

\begin{abstract}
Resumo
Os desafios do processo de ensino e aprendizagem em Ciências Biológicas tem aumentado em conjunto com o surgimento das Novas Metodologias para o ensino. O estudo em Biologia mostra que a necessidade de elaborar propostas que busquem uma maior integração entre aluno e professor de forma a dinamizar a construção do conhecimento em Biologia. O objetivo deste trabalho é analisar como ocorre os mecanismos da colaboração na construção do conhecimento em Biologia em ambiente virtual, em acadêmicos de Ciências Biológicas da UEMG Unidade Carangola. Com a utilização de métodos abordados em metodologias usuais da pesquisa qualitativa, foram utilizadas duas questões problemas em acadêmicos do curso de Ciências Biológicas da Universidade do Estado de Minas Gerais (UEMG) Carangola. A coleta de dados foi propiciada pela criação de salas virtuais na Plataforma Moodle. A partir das interações entre os acadêmicos, foram elaborados arquivos que com a utilização do programa NVIVO, permitiram a elaboração de códigos e categorias que propiciaram as discussões do trabalho. Os dados mostram que incentivados por nossa proposta os alunos desenvolveram esquemas em colaboração, de forma espontânea, que permitiram a conclusão da proposta. Fica claro em nossa proposta que o desafio de buscar novas proposições para o processo da construção do conhecimento em Biologia, traz vantagens significativas para os educandos e permitiu ao professor, uma maior integração frente aos conteúdos ensinados em sala de aula. Acreditamos que a proposta contribuiu significativamente para os alunos apreenderem os conteúdos em Biologia.
\end{abstract}

Palavras-chave: Educação; Colaboração; Ciências biológicas; Novas tecnologias.

\begin{abstract}
The challenges of the teaching and learning process in Biological Sciences have increased together with the emergence of New Methodologies for teaching. The study in Biology shows the need to develop proposals that seek a greater integration between student and teacher in order to streamline the construction of knowledge in Biology. The objective of this work is to analyze how the mechanisms of collaboration occur in the construction of knowledge in Biology in a virtual environment, among Biological Sciences' students from UEMG - Carangola Unit. With the use of methods addressed in usual methodologies of qualitative research, two questions were used problems in students of the Biological Sciences course at the University of the State of Minas Gerais (UEMG) Carangola. Data collection was facilitated by the creation of virtual rooms on the Moodle platform, from the interactions between the students, files were prepared using the NVIVO program, which allowed the development of codes and categories that provided the discussions of the work. The data show that, encouraged by our proposal, the students developed collaborative schemes, in a spontaneous way, which allowed the conclusion of the proposal. It is clear in our proposal that the challenge of seeking new propositions for the process of knowledge construction in Biology brings significant advantages for the students and allowed the teacher a greater integration with the content taught in the classroom. We believe that the proposal contributed significantly to the students' apprehension of the contents in Biology.
\end{abstract}

Keywords: Education; Collaboration; Biological sciences; New technologies. 


\begin{abstract}
Resumen
Los retos del proceso de enseñanza y aprendizaje en Ciencias Biológicas han aumentado junto con la aparición de Nuevas Metodologías para la enseñanza. El estudio en Biología muestra la necesidad de desarrollar propuestas que busquen una mayor integración entre el alumno y el profesor para agilizar la construcción del conocimiento en Biología. El objetivo de este trabajo es analizar los mecanismos de colaboración en la construcción del conocimiento en Biología en un entorno virtual, en estudiantes de Ciencias Biológicas de la UEMG - Unidad Carangola. Con el uso de métodos abordados en las metodologías habituales de la investigación cualitativa, se utilizaron dos preguntas problemas en los estudiantes del curso de Ciencias Biológicas de la Universidad del Estado de Minas Gerais (UEMG) Carangola. La recolección de datos se habilitó mediante la creación de salas virtuales en la Plataforma Moodle, a partir de las interacciones entre los académicos, se elaboraron archivos utilizando el programa NVIVO, lo que permitió la elaboración de códigos y categorías que proporcionaron las discusiones del trabajo. Los datos muestran que, animados por nuestra propuesta, los alumnos desarrollaron esquemas de colaboración, de forma espontánea, que permitieron la conclusión de la propuesta. Queda claro en nuestra propuesta que el desafío de buscar nuevas proposiciones para el proceso de construcción del conocimiento en Biología, trae ventajas significativas para los alumnos y permitió al profesor una mayor integración con los contenidos impartidos en el aula. Creemos que la propuesta contribuyó significativamente a la aprehensión de los contenidos en Biología por parte de los alumnos.
\end{abstract}

Palabras clave: Educación; Colaboración; Ciencias biológicas; Nuevas tecnologías

\title{
1. Introdução
}

Buscar novas formas de ensinar, tornar o aprender um processo contínuo, fazer do ensino e da aprendizagem um processo dinâmico, em que os participantes verdadeiramente contribuam e atuem no processo. Estes são os desafios da educação, mostrar quanto pode ser enriquecedor a construção do conhecimento e seu dinamismo melhorar a aprendizagem em todos os níveis.

De acordo com Torres e Irala(2007) esse dinamismo ao ensinar e aprender agregam para os alunos níveis maiores de responsabilidade em relação à aprendizagem, levando a construção e assimilação dos conceitos e permitindo a uma solidificação dos conhecimentos de uma maneira mais autônoma.

A aprendizagem colaborativa e a aprendizagem cooperativa quando analisadas no ambiente acadêmico, passam por uma grande valorização ao proporcionar a visão de que essas metodologias tem favorecido uma aprendizagem mais ativa por meio do estímulo em vários aspectos: do pensamento crítico; desenvolvendo melhor interações entre acadêmicos e professores, o processo de intercâmbio de informações para resolução de problemas e ao final levar a uma melhor capacidade de regular e dinamizar o processo de ensino aprendizagem (Torres \& Irala 2007).

Almeida(2005), Valente(2005), Camas(2002), Mengalli, Camas, (2013) citam a possibilidade de utilizar um ambiente virtual de aprendizagem (AVA) como ampliação dos espaços de aprendizagem, rompendo a limitação espaço-temporal da aula e permitindo a abertura a uma sala de aula online, não restrita à temporalidade do espaço físico. Além de ser um ambiente de interação que permite a comunicação bidirecional entre professor-aluno e aluno-aluno, de forma síncrona e assíncrona, utilizando ferramentas tecnológicas de aprendizagem colaborativa.

A integração das Tecnologias da informação e comunicação (TICs) à educação, segundo Belloni (2009, p. 11) deve ser realizada “em sua dupla dimensão: como ferramentas pedagógicas e como objetos de estudo". Assim, a tecnologia em sala de aula precisa ser usada de forma adequada, com professores preparados para o uso pedagógico, pois quando usadas de forma errada, essas ferramentas podem causar distrações e acabar com todo o planejamento e objetivo da aula.

Nesse sentido, entendemos que o professor ao integrar as TICs ao cotidiano da escola, na sala de aula, deve fazê-lo de modo criativo, crítico, competente, de forma a auxiliar o desenvolvimento dos conteúdos disciplinares e possibilitar a seus alunos o desenvolvimento de habilidades e melhorias significativas ao processo de ensino-aprendizagem. 


\subsection{A Aprendizagem E O Trabalho Colaborativo}

$\mathrm{O}$ uso das TICD, por meio de ambientes virtuais de aprendizagem, segundo BARRETO (2010, p. 6), "tem possibilitado, de forma fácil e rápida, a interação entre os autores envolvidos no processo, através de ferramentas que, cujas atividades e ações educacionais dirigidas, podem potencializar ou não o processo de aprendizagem"

Hine (2005), afirma que o ciberespaço se torna um meio rico para a comunicação. Partindo do momento em que congrega um grande número de usuários na complexidade das relações de comunicação estabelecidas, molda-se como um ambiente privilegiado trabalhos colaborativos. O contexto online como um contexto e artefato cultural, para os educandos, é muito mais comum do que para os professores.

Fica claro que ao se tratar da aprendizagem colaborativa, deve-se ter em mente que a mesma não depende da tecnologia para que possa ocorrer. Mas a medida que popularização e a massificação da Internet ocorreu, torna-se necessário a viabilização de um tipo de ambiente colaborativo, em que fique claro o oferecimento de vantagens para a construção do conhecimento (Damiani, 2008).

Segundo Damiani (2008), a utilização combinada da tecnologia aplicada à aprendizagem colaborativa. Pode potencializar situações propícias para que alunos e professores, troquem informações, pesquisem. A partir dessas interações, construam individual e coletivamente seus conhecimentos. Ainda de acordo com Damiani (2008), fica claro que os dispositivos eletrônicos, como computadores e tablets podem e devem ser considerados como um recurso para a aprendizagem colaborativa, pois se adequam à organização de várias e diversificadas atividades. Permitindo ainda ser um mecanismo de colaboração entre os educandos colaborem uns com os outros nas atividades de grupo.

Behrens (2003b), afirma que com a massificação do uso da Internet e a partir de critérios em sua utilização, esta possa representar um instrumento significativo dentro do processo educativo como um todo, por propiciar a criação de ambientes ricos, motivadores, interativos, colaborativos.

Ressaltamos ainda que, igualmente como acontece em mecanismos presenciais, em uma aula online, "a aprendizagem colaborativa deve ser planejada e "facilitada" porque ao se tomar esses cuidados tornam-se claros os objetivos que se precisam e se buscam ser atingidos.

Interessante o proposto por Johnson e Johnson (2001) ao relatarem sobre a aprendizagem cooperativa e a resolução de conflitos afirmam:

\footnotetext{
"A aprendizagem cooperativa tem um corpo considerável de pesquisa validando sua efetividade. Nos últimos 90 anos 550 estudos foram administrados comparando a efetividade relativa da aprendizagem cooperativa, aprendizagem competitiva, e da aprendizagem individualista. A aprendizagem cooperativa melhora consistentemente a realização e a retenção, cria relações mais positivas entre os estudantes, e promove saúde psicológica e autoestima dos estudantes. Nós sabemos mais da aprendizagem cooperativa do que sabemos sobre qualquer outro aspecto de ensino e aprendendo". (Johnson \& Johnson 2001, p. 1)
}

Ressaltamos aqui que ao analisar a proposta de aprendizagem dentro deste conceito, entendo que a dinâmica muda de uma perspectiva individual e isolada para uma aprendizagem em grupo, isolando a valorização excessiva do trabalho independente, e apoiando em maior grau os aspectos voltados para a colaboração.

"Quando os alunos trabalham em conjunto, isto é, colaborativamente, produzem um conhecimento mais profundo e, ao mesmo tempo, deixam de ser independentes para se tornarem interdependentes" (Pallof \& Pratt, 2002, p. 141).

Dentro dessa colocação entendemos a validação do trabalho colaborativo, como forma de integrar diferentes percepções no processo de construção do conhecimento e da valorização do educando em suas percepções. 


\subsection{Mecanismos de aprendizagem colaborativa em ambientes virtuais}

O surgimento do Ambiente Virtual de Aprendizagem e das comunidades virtuais assumiu um significativo interesse para a Educação e o Ensino, principalmente quando se tenta compreender de que forma se constitui a aprendizagem colaborativa dentro destes ambientes.

Interessante ressaltar o número de trabalhos em que tem se debruçado e debatido sobre o uso das Tecnlogias da Informação e Comunicação (TICs) na educação (Garcia \& Lins 2008, Gutierrez 2005, Dotta 2011, Teixeira et. al. 2011) nos quais se percebe uma interessante avaliação da influência da utilização dos dispositivos.

Flores e Becerra (2002) apresentam estratégias de aprendizagem em colaboração mediadas por tecnologias visando à produção social do conhecimento na Universidade Virtual de Quilmes (UVQ). Ao desenvolverem essa experiência, os autores partiram do princípio que propostas inovadoras e uma produção de material didático criteriosa foram capazes de gerar nos estudantes significativos processos de reflexão, análise crítica e garantiram o estabelecimento de relações entre "o que sabem e o novo conteúdo a aprender".

Essa percepção ratifica o que se tem visto nos trabalhos sobre o uso de novas tecnologias na educação em que segundo os autores torna-se urgente a necessidade de o uso das TIC ser acompanhado por mudanças nas propostas de trabalho e que busquem se afastar dos modelos tradicionais de ensino e de aprendizagem (Santos \& Weber, 2013).

Ao analisarmos a validação dos benefícios das interações entre educandos no desenvolvimento dos processos de sua aprendizagem, encontramos respaldos em diversos trabalhos com resultados ricamente debatidos como os trabalhos de candela (2000) e López de Lara (2000), Ambrosetti (1999), costa et.al 2016, Souza et.al. (2016). importante ressaltar que seguimos os preceitos de Creswell(2015) em relação ás abordagens da pesquisa qualitativa.

O objetivo deste trabalho é analisar como ocorre os mecanismos da colaboração na construção do conhecimento em Biologia em ambiente virtual, em acadêmicos de Ciências Biológicas da UEMG Unidade Carangola.

\section{Metodologia}

Para realização da pesquisa, o projeto foi submetido ao Comitê de Ética em Pesquisa em Seres Humanos, da UEMG, via Plataforma Brasil, sendo recepcionado em 14/09/2016, $\mathrm{n}^{\circ}$. 094252/2016 e recebendo o parecer consubstanciado $\mathrm{n}^{\mathrm{o}}$ : 1.821.685 em 16/11/2016 (Anexo A).

Neste trabalho, propomos a resolução de questões problemas em Biologia. A construção das questões problemas foi baseada nas disciplinas de Anatomia Humana, Parasitologia, Microbiologia e Botânica, sendo três destas disciplinas, ministradas por mim no curso de Ciências Biológicas da UEMG Carangola.

A aplicação das questões problemas ocorreu no $2^{\circ}$ semestre do ano letivo de 2017, no período de 12/10/2017 a 20/11/2017, nas turmas do segundo e quarto períodos do Curso de Ciências Biológicas da Universidade do Estado de Minas Gerais - Unidade Carangola (UEMG CARANGOLA).

Os alunos foram cadastrados nos ambientes virtuais das salas, uma para cada tarefa (questão problema), na Plataforma Moodle da Universidade do Estado de Minas Gerais - UEMG, sendo alocados conforme o períodos que estavam cursando. Após o cadastro das turmas, os alunos receberam as orientações para desenvolvimento dos trabalhos, e cada turma recebeu o problema gerador específico. Cada período possuiu uma sala no ambiente virtual, na página virtual da UEMG.

As interações ocorreram em sua maioria de forma assíncrona, ou seja, não havia um horário estipulado para que os acadêmicos entrassem na Plataforma Moodle e registrassem suas interações. Em alguns momentos as interações ocorreram de forma síncrona entre os alunos e com minha presença.

Por fim demos início ao trabalho de campo com a coleta de dados e consequente análise com o auxílio do software NVIVO. 
Como forma de facilitar o processo de análise das interações realizamos um estudo sobre as bases da Pesquisa Qualitativa e suas várias abordagens incluindo o método de Análise de Conteúdo para tratamento dos dados. A partir deste estudo optamos pela abordagem de Teoria Fundamentada em Dados (Grounde Theory), que nos permitiu reunir fundamentações teóricas que nos auxiliaram na condução da pesquisa de campo e em nossas discussões frente aos objetivos de nossa pesquisa.

\subsection{Instrumentos de Coleta}

Utilizamos em nosso trabalho como instrumento de coleta, questões problemas contextualizadas, com as disciplinas ministradas para os períodos do curso de Ciências Biológicas da UEMG, unidade Carangola. Para cada período foi proposto uma questão relacionada a disciplina de Anatomia humana, para o primeiro período de Ciências Biológicas e Parasitologia para o segundo período do Curso. Abaixo encontram-se descritas as questões problemas.

\subsubsection{Questão Problema 1:}

- Para melhorar o entendimento sobre as variedades morfológicas anatômicas existentes nos seres humanos (comprimento dos ossos) um professor lançou o desafio para os estudantes que chamou de Questão Problema 1. Duas pessoas de alturas diferentes $(1,70 \mathrm{~m}$ e 2,00m) caminham todos os dias a mesma distância até seu local de trabalho. Ambos moram há mesma distância do local de trabalho, aproximadamente 3 quilômetros. Sabe-se que os ossos possuem uma proporção em relação a altura final, qual dos dois gasta menos tempo para chegar ao trabalho, justifique utilizando os critérios anatômicos de postura e movimento. Conhecendo a altura de cada um e o cumprimento das pernas, determine o número de passos que cada um daria ao final de um dia, indo e voltando para casa.

\subsubsection{Questão Problema 2:}

- Uma pessoa, moradora de uma região sem saneamento básico, ingere alimentos contaminados com ovos de Ascaris lumbricoides. Sabendo que cada fêmea adulta coloca em torno de 27.000 ovos por dia, ao final de um ano. No ritmo de ovoposição, ao final de 12 meses, quantas pessoas poderiam ser infectadas com apenas uma fêmea adulta? Em uma sala de aula, com 30 alunos, após realização de um exame parasitológico, foi detectado que três alunos apresentavam ovos de Ascaris em suas fezes. Determine ao final de 30 dias o potencial de disseminação dos ovos, por esses três alunos. Considere que os dois alunos apresentaram em suas fezes, após a realização de um exame, uma presença significativa dos ovos.

\section{Análise dos Dados}

Os registros das interações dos alunos na Plataforma Moodle referente às discussões das diversas situações problema foram transcritos em um arquivo tipo "doc" como já foi apontado. Este Arquivo foi "importado" para o programa NVIVO, de modo a auxiliar na organização dos dados. A respectiva análise ocorreu segundo as proposições de Bardin (2011). Essas proposições são: a) Transcrição das interações dos acadêmicos, b) Leitura e análise dos registros escritos,c) determinação das palavras chave,d) elaboração dos códigos,e) criação das categorias, f) geração dos temas

Para facilitar a compreensão de como foi feita a análise dos dados passamos a descrever por meio de um recorte, as diversas fases da análise de acordo com o procedimento já descrito com a utilização do Programa NVIVO. O tratamento dos dados seguiu os passos seguintes: 1) Transcrição dos questionários respondidos pelos educandos para um arquivo tipo doc; 2) Leitura de todas as interações transcritas; 3) Criação do projeto para análise das interações de cada questão problema no NVIVO. 4) Importação do arquivo com as transcrições das entrevistas para o NVIVO. 5) Seleção das palavras-chave.6) Definição dos Códigos e Categorias. 7) Seleção dos temas. 


\section{Resultados e Discussão}

Na questão problema 1 tivemos a participação de 23 alunos e 83 interações. Na questão problema 2 aplicada, alunos do quarto período, tivemos a participação de 18 alunos e 82 interações, No total 165 interações que formaram nosso banco de dados.

Por se tratar de uma análise qualitativa, partindo dos pressupostos da Pesquisa Qualitativa, em nossa análise sobre o processo de colaboração entre os educandos na construção do conhecimento em Biologia.

Com a utilização do programa NVIVO, pudemos destacar as palavras-chave, sendo "arrastadas" para um conjunto de ideias de "mesmo significados" que denominamos códigos. A tela correspondente a esse processo está exemplificada na Figura 1.

Figura 1 - Tela apresentando seleção de palavras-chave no NVIVO.

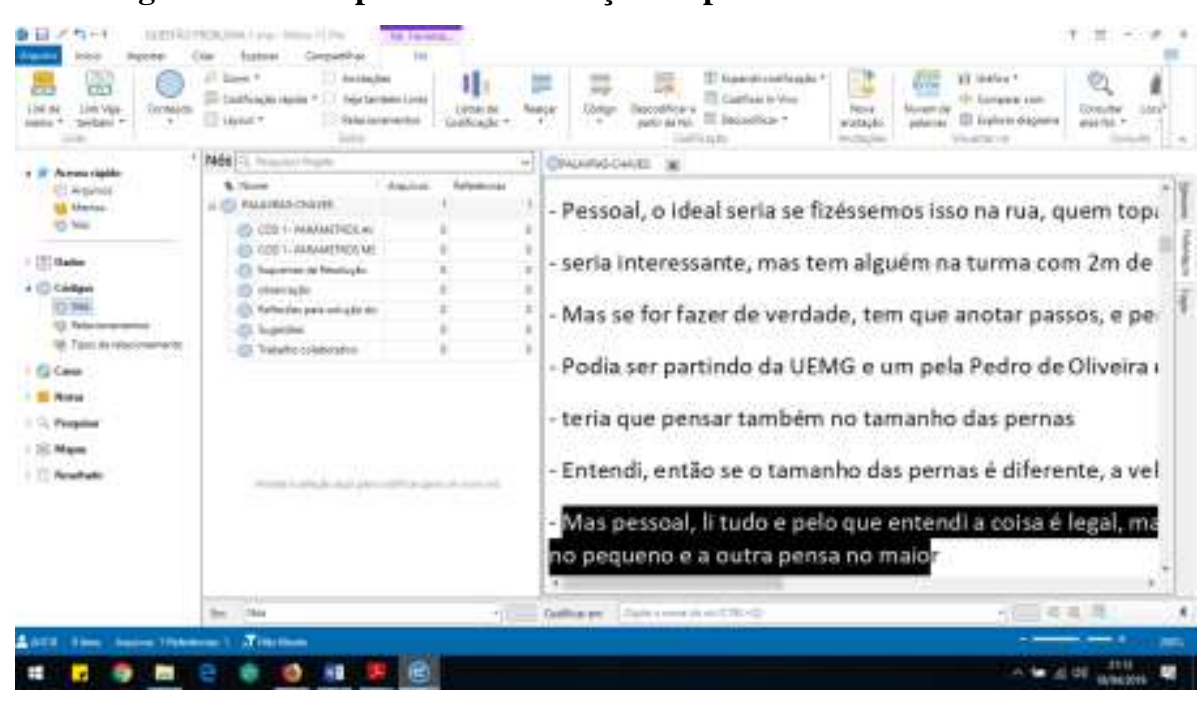

Fonte: Autores.

Segundo este procedimento, nesta questão foram estabelecidos 5 códigos: Parâmetros Avaliativos, Observações dedutivas, Organização metodológica, Integrações colaborativas, Envolvimento com a matemática. A figura 2 destaca as palavras chave relacionadas ao trabalho colaborativo apresentando de maneira esquemática as palavras-chave que o aplicativo NVIVO, "armazena" em cada nó e que chamamos de códigos. 
Figura 2 - Códigos emergentes das palavras-chave da questão problema 1.

\section{PALAVRAS-CHAVE}

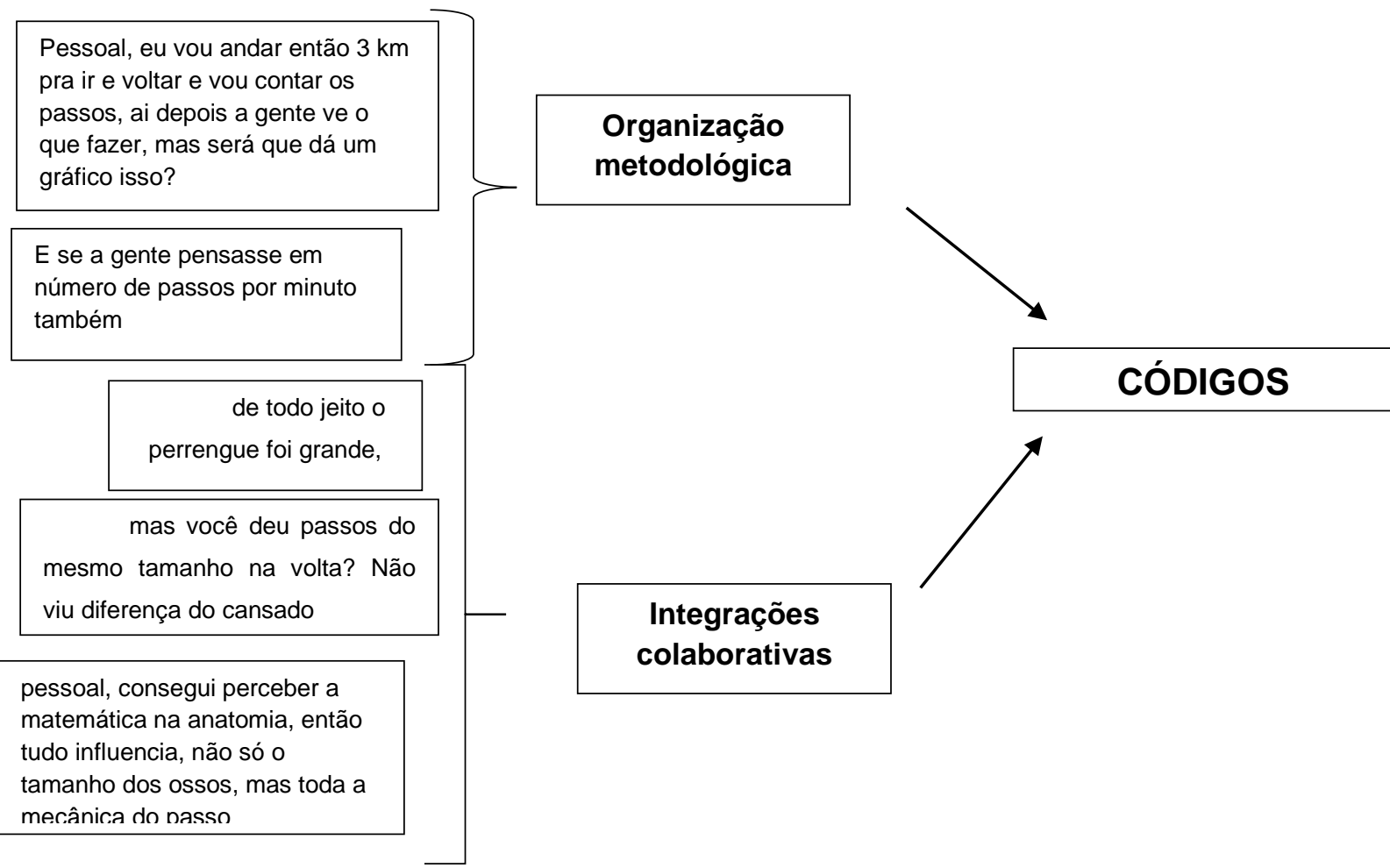

Fonte: Autores.

Finalizada a etapa da criação dos códigos buscamos, pelo mesmo processo, o estabelecimento das categorias que podem ser visualizadas na Figura 3.

Figura 3 - Categorias emergentes dos códigos na questão problema 1-

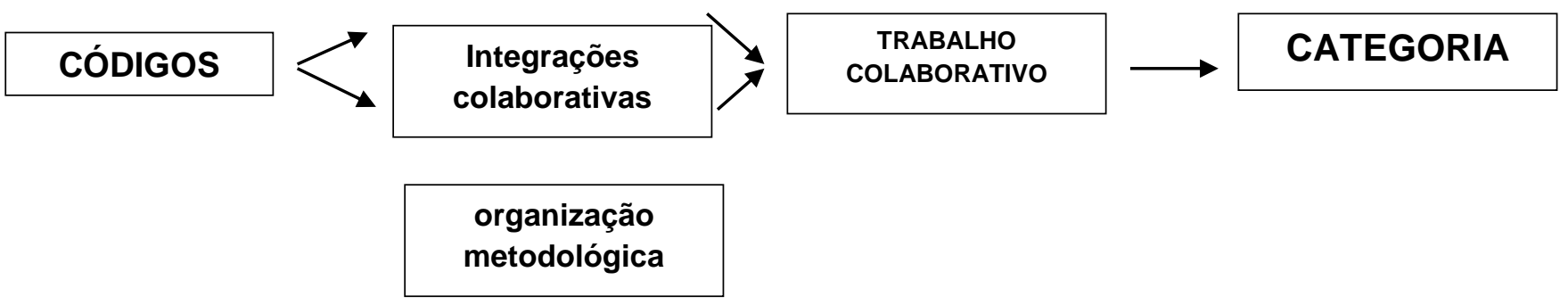

Fonte: Autores.

Analisando as categorias, procuramos observar de que forma os acadêmicos interagiam e como isso contribuía para a solução das situações problemas.

Interessante é a maneira como os educandos tomaram frente à questão problema 1: a percepção dos mesmos em relação à necessidade de interação com a proposição e a forma como a tomada de decisões acontecia de forma espontânea. As contribuições foram sendo colocadas de maneira a serem integradas buscando a colaboração de cada um no processo como um todo.

Ao analisarmos o processo de construção do conhecimento, devemos observar sua relação intrínseca com as ferramentas utilizadas, entendemos que para que ocorra uma aprendizagem significativa o educando deve estar familiarizado 
com a proposta de ensino, e conseguir visualizar significados concretos que possam permitir que ele assuma a direção da construção do conhecimento.

Observamos que livres dos livros didáticos e das amarras do formato tradicional, os educandos experimentaram melhor as formas de resolução dos problemas e vivenciaram melhor a troca de informações entre eles.

Aluno 06-Pessoal, o ideal seria se fizéssemos isso na rua, quem topa, a gente marca o mesmo local pra ir e voltar

Aluno 09- Mas se for fazer de verdade, tem que anotar passos, e pensar em dois trajetos diferentes com a mesma distância

Aluno 07- Podia ser partindo da UEMG e um pela Pedro de Oliveira e outro pela rua do colégio, partindo da ponte, teria a mesma distância

- teria que pensar também no tamanho das pernas

Aluno 12- Entendi, então se o tamanho das pernas é diferente, a velocidade é diferente

aluno 09-Mas pessoal, li tudo e pelo que entendi a coisa é legal, mas dá trabalho, mas eu topo a gente fazer isso de verdade, vamos nos separar, uma parte pensa no pequeno e a outra pensa no maior

Neste ponto, ao desenvolvermos nossa proposta em um ambiente virtual, concordamos com Braga (2012), quando afirma que um suporte didático virtual pode ser considerado como um mediador. Para isso, o professor deve ser capaz de oferecer alguns estímulos para que o aprendiz possa elaborar a partir da experiência, construindo novos conhecimentos e novos conceitos

Importante destacar neste ponto é a autonomia dos educandos, os mesmos ao se depararem com a questão problema, interagiram de forma significativa, demostrando a autonomia necessária e adequada para a resolução da questão.

Ressaltamos aqui o proposto por Linard (2000), que revela que a autonomia, é exigida do aprendiz na formação por meio de um Ambiente Virtual de Trabalho logo no início do processo. Caso contrário, algum estilo de aprendizagem, uma má gestão do tempo ou uma má percepção do ambiente podem atrapalhar a aprendizagem ou mesmo levar ao abandono da formação.

Ao analisarmos a categoria Trabalho colaborativo, observamos como as interações entre os educandos foram proporcionando uma coesão maior na busca pela resolução do problema. Um importante fato a ser destacado é a facilidade com que as interações colaborativas aconteceram.

Os alunos se mostraram muito receptivas às interações. Não foi percebido nenhum aspecto competitivo ou depreciativo nas interações, mas sim integrativo, mostrando a viabilidade do trabalho em ambiente virtual e a forma espontânea que interagiam. As interações abaixo evidenciam a troca de informações de forma colaborativa e integrativa: 
Aluno 23-- Eu tava pensando no seguinte, se a alguém for da ponte quebrada até o sinal la no final da rua do barracão, teria $3 \mathrm{~km}$ eu acho né...como vamos medir distância? E do outro lado poderia ser pela Pedro de oliveira, até o mesmo sinal, será que tem a mesma distância?

Aluno 08 -Que isso, so você pensar que pra andar precisa de muito calculo né

Aluno 25- Acho que esses dois caminhos são legais de pensar, ou a gente parte da UEMG e uma pessoa vai pela ponte quebrada e rua do barracão e outro direto pela Pedro de oliveira, conta os passos e o tempo, ai a gente tem um ponto de partida....

Aluno 17-Já seria alguma coisa, mas pessoal, tava lendo o enunciado, se a gente pensar bem na coisa, ta lá dizendo ao final de um dia, então a pessoa, foi trabalhar, voltou pro almoço, foi depois do almoço e voltou ao final do dia, a gente vai multiplicar essas idas e vindas?

Aluno 13-Pessoal, eu vou andar então $3 \mathrm{~km}$ pra ir e voltar e vou contar os passos, ai depois a gente ve o que fazer, mas será que dá um gráfico isso? E se a gente pensasse em número de passos por minuto também

Jesus et al.(2016) e Seixas et.al.(2012) ressaltam a importância da colaboração em ambientes virtuais na construção do conhecimento, pois permite ao aluno identificar o que é importante e ainda perceber que por este meio o mesmo visualiza o processo de aprendizagem e ainda reconhecendo que a educação muda a todo instante.

Ao percebermos as interações nesta categoria, destacamos que a proposta em ambiente virtual propiciou de forma lúdica uma integração colaborativa, sendo o processo prazeroso para os acadêmicos. Este fato nos coloca em concordância com Ribeiro et.al.(2007) que afirma que a aprendizagem deve buscar sempre ser dinâmica, eficaz e lúdica.

Analisando essa categoria, concordamos com o proposto por Soares et.al. (2017), ambientes virtuais, no contexto deste estudo, são espaços de aprendizagem na web em que os interlocutores do processo interagem entre si, cooperando e desenvolvendo ideias, ultrapassando fronteiras geográficas, culturais, de idade e de tempo, para construir aprendizagens significativas.

Os autores destacam que a dinâmica desses ambientes é construída tendo como fonte a comunicação entre alunos e professores que formam os fluxos de interação, os quais sustentam o desenvolvimento dos contextos de aprendizagem.

Nossa concepção é que em nosso trabalho as interações demonstram a percepção do "outro" como alguém válido de contribuição, alguém que pode verdadeiramente dar significado ao que foi proposto por alguém anteriormente. E nos mostra que as interações foram acontecendo sem centralização, com respeito mútuo, com suspensão de julgamento, aceitação da diferença, presença sem exigência, livre expressão de ideias e sentimentos aos parceiros.

Nesse ponto destacamos Maturana e Varella Garcia (2002), afirmando que se abre em um ambiente virtual "um espaço de interações recorrentes com o outro, no qual sua presença é legítima, sem exigências.

Analisando a questão dois de nosso trabalho, apresentamos e destacamos as palavras-chave em conjunto com criação dos respectivos códigos referentes a questão problema 2, quando da utilização do NVIVO.

galera, pensando aqui, esses números dao ideia pra gente de como é importante estar ligado nas paradas de números 
Figura 4 - Definição dos códigos na questão problema 2, a partir das interações dos educandos.
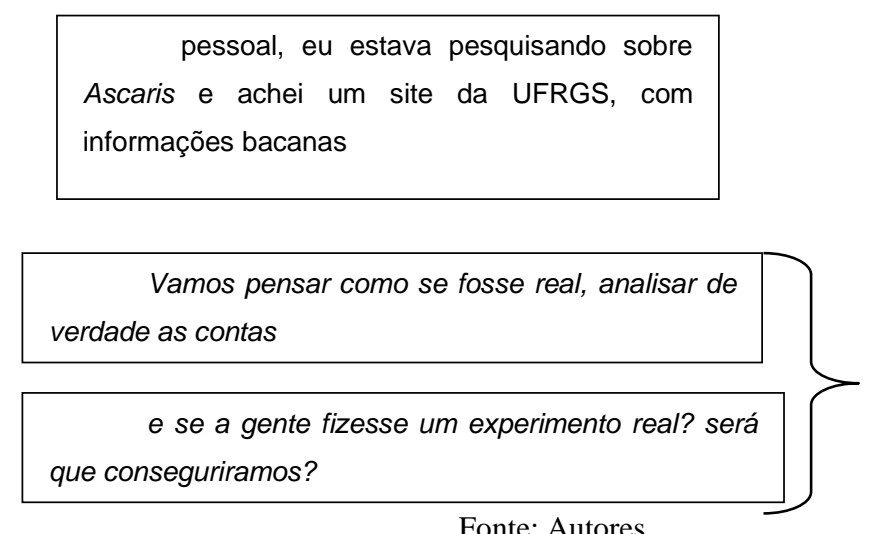

Fonte: Autores.

\section{Integração \\ Colaborativa}

\section{Palavras-chave}

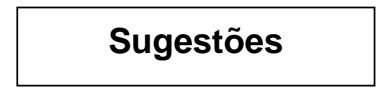

Gil-Pérez e Martínez Torregrosa (1983, 1992) concebem a resolução de problemas como um processo que reproduz procedimentos de uma pesquisa científica. Entendemos que a resolução de um problema, de acordo com nossa concepção, pode ser compreendido como uma situação que envolve dificuldades, para as quais não se possui soluções previamente conhecidas.

Esses problemas não teriam respostas conhecidas a priori, por conseguinte os estudantes precisariam mobilizar competências para enfrentar questões propostas quer pelos professores, quer pelas situações do dia-a-dia. Consideramos essa premissa como uma das bases de nossos estudos.

Souza, Rozal(2016) e MalheiroS (2011) consideram todo processo experimental como uma ação investigativa. Nas atividades envolvidas na resolução da proposta poderão contribuir para que os estudantes desenvolvam com presteza suas habilidades cognitivas. Mas para que isso aconteça é importante que o professor não perca de vista que a participação dos alunos em todas as fases (inclusive sua proposição) dos procedimentos de resolução do problema seja um fator essencial para a concretização desse objetivo.

De encontro com o proposto por Valverde (2005), exigir um maior esforço mental dos alunos durante os processos experimentais investigativos significa que os educandos devem desenvolver habilidades cognitivas. E ao serem capazes de estabelecerem conexões, argumentações e ao propor soluções para o problema, percebemos que as habilidades cognitivas foram sendo adquiridas e confirmadas, o que corrobora os pressupostos de Suart e Marcondes (2008), ao afirmarem que tendo cumprido essas etapas, pode-se proporcionar aos alunos a ampliação de suas habilidades cognitivas contribuindo para o seu desenvolvimento conceitual.

Leite (2001) em seu trabalho afirma que não importa se as hipóteses que são apresentadas pelos acadêmicos eram certas ou erradas, pois o que deve ser levado em conta a priori é o estímulo à prática de fazer previsões. Procedimento indispensável para adquirir, formar e adaptar os conhecimentos à sua maneira de pensar.

Mas para que se chegue ao objetivo final é importante que as estratégias planejadas possam ser testadas e executadas. Os dados coletados devem ser examinados (confirmados ou refutados) durante o percurso de resolução. Ao longo de nosso trabalho pudemos verificar, por meio de várias interações, os educandos executando o trabalho e validando suas afirmações e conclusões, conforme podemos observar nas interações abaixo: 


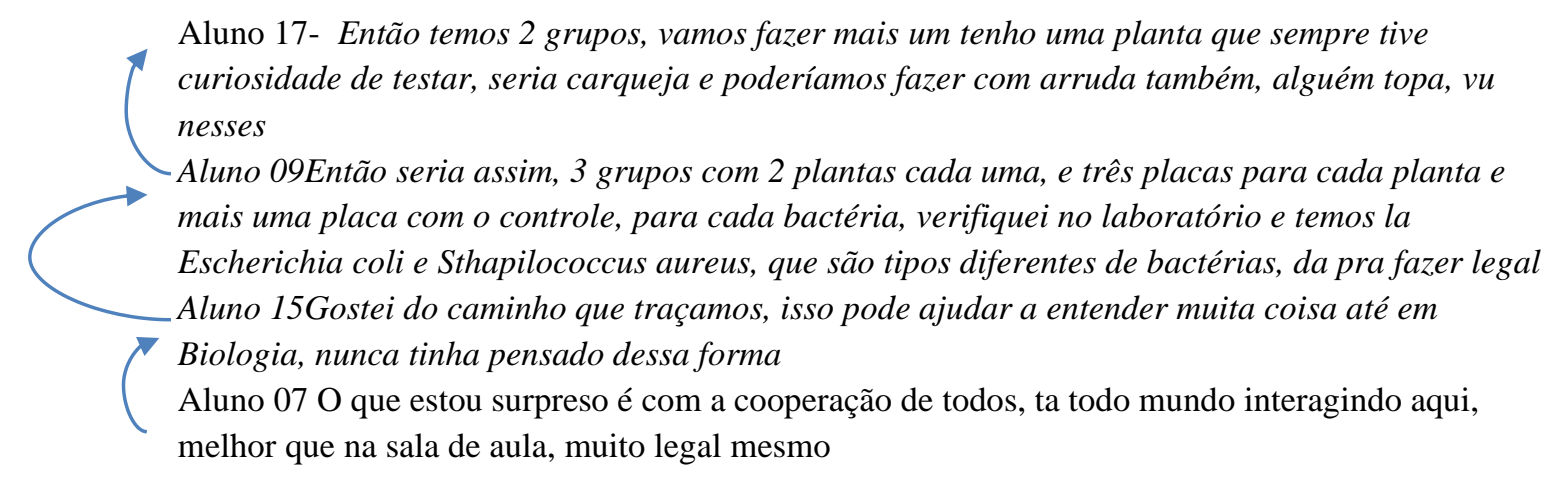

Ao percebermos essas interações concordamos com Segura e Kalhil (2015) e Silva , Khalil (2017) que propõem que quando o estudante interage com o assunto em estudo, ouvindo, perguntando, discutindo, fazendo e ensinando, tornando-se capaz de produzir conhecimento ao invés de recebê-lo de forma passiva. Isto tudo independentemente do método ou estratégia utilizada para promover a aprendizagem significativa.

Para Pecotche (2011) a utilização das funções mentais como pensar, raciocinar, observar, refletir, entender, combinar, dentre outras, formam o que ele denomina de atitude ativa da inteligência, em contraposição a atitude passiva geralmente vinculada aos métodos tradicionais de ensino. Nesse ponto, destacamos a capacidade de análise dos educandos, a busca por significados elaborados a partir da questão problema, e a forma como a comunicação de sua proposição acontecia.

Isto posto vamos ao encontro do proposto por Oliveira (2013), quando pondera que a capacidade de analisar o caso conferindo-lhe um significado e a capacidade de comunicar seu pensamento de maneira clara e efetiva são dois aspectos importantes trabalhados durante essa atividade.

Relevante ressaltar que Peixoto (2016) afirma que para atingir novos patamares de pensamento, devemos entender de forma indispensável que o debate entre os pares precisa superar a simples justaposição de ideias. Fato que proporciona no estudante aumentar a flexibilidade mental mediante o reconhecimento da diversidade de interpretações diante do mesmo assunto.

\section{Conclusão}

Este trabalho procurou compreender como ocorre o processo de construção do conhecimento em Biologia em ambiente virtual, em acadêmicos de Ciências Biológicas da UEMG Carangola. O processo foi analisado dentro das interações empreendidas pelos participantes do projeto, com destaque para as ações e a produção discursiva que emanou dessa interação.

Compreendemos nesse momento que há uma necessidade maior da compreensão que os Ambientes virtuais de aprendizagem e suas ferramentas são um instrumento que auxiliam o professor em sua prática de ensino.

Destacamos em nosso trabalho que a construção do conhecimento em Biologia em ambiente virtual, ocorreu de maneira significativa. Os educandos apropriaram-se das ferramentas oferecidas e dinamicamente desenvolveram as estratégias para a resolução das questões problemas. Verificamos que no ambiente virtual as interações e as inter-relações entre os educandos foram intensas e em muitos casos, quando comparadas com o ambiente presencial, mais valorizadas.

As evidências do trabalho colaborativo, onde as interações colocadas, eram acrescidas ao trabalho de todos e convergiam para o mesmo ponto de condução da resolução.

Este trabalho é parte dos estudos de doutorado e uma proposta de continuidade de trabalhos é a ligação entre este trabalho com o movimento BTSK Biology Teacher's Specialized Knowledge, visando entender as contribuições a respeito da construção do conhecimento em Biologia. 
Ao finalizarmos nosso trabalho destacamos que a construção do conhecimento em Biologia em ambiente virtual ocorreu de maneira significativa. Os educandos apropriaram-se das ferramentas oferecidas e dinamicamente desenvolveram as estratégias para a resolução das questões problemas. Verificamos que no ambiente virtual as interações e as inter-relações entre os educandos foram significativas, e em muitos casos, quando comparadas com o ambiente presencial, mais valorizadas.

\section{Agradecimentos}

Este trabalho de pesquisa é fruto de esforços da CAPES- Coordenação de Aperfeiçoamento de Pessoal de Nível Superior - na outorga de bolsa para Pós-Doutorado Sênior no exterior Processo BEX 1471/14-7.

\section{Referências}

Almeida, L. M. W., Silva, K. P., \& Vertuan, R. E. (2016) Modelagem Matemática na Educação Básica. Contexto.

Ambrosetti, N. B. (1999) O “eu” e o "nós": trabalhando com a diversidade em sala de aula. In: ANDRÉ, M. (Org.). Pedagogia da diferenças na sala de aula. Papirus.

Bardin, L. (2011) Análise de conteúdo. Edições 70.

Barreto, A. L. de O. (2010) Ambientes virtuais de aprendizagem: uma experiência de formação continuada de professores. 2010.142 f. Dissertação (Mestrado em Ensino de Ciências na educação Básica) - Universidade do Grande Rio "Prof José de SouzaHerdy",

Behrens, M. A. (2003). Projetos de aprendizagem colaborativa num paradigma emergente. In: Moran, J. M., Masetto, M. T., Behrens, M. A. (Orgs.). Novas tecnologias e mediação pedagógica. (7a ed.), Papirus, 67-132.

Belloni, M. L. (2009) O que é mídia-educação. (3a ed.), Autores Associados, 102 p.

Braga, E. M. (2012). Os elementos do processo de ensino-aprendizagem: Da sala de aula à educação mediada pelas tecnologias digitais da informação e da comunicação (TDICs). Revista Vozes dos Vales da UFVJM: Publicações Acadêmicas. n.2 Ano I.

Camas, N. P. V. (2002) Educação a Distância em Realidades Virtuais: a postura do professor do Ensino Superior ante as novas tecnologias facilitadoras de formação continuada. 157 f. Dissertação (Mestrado em Educação) - PUC-Campinas.

Candela, A. (2000) Co-construcción de conocimiento en contextos escolares. In: Conferência De Pesquisa Sócio-Cultural, 3, Campinas, Anais... Campinas. 138.

Costa, C. R. et.al. (2016) Trabalho colaborativo entre o professor do ensino comum na interface educação física e atendimento educacional especializado. Revista Educação Online, (21), 151-185.

Creswell, J. (2015). Educational Research: Planning, Conducting, and Evaluating Quantitative and Qualitative Research. Pearson.

Damiani, M. F. (2008) Entendendo o trabalho colaborativo em educação e revelando seus benefícios. Educar, Editora UFPR. 31, $213-230$.

Dotta, S. (2011) “Uso de uma Mídia Social como Ambiente Virtual de Aprendizagem”. In: XXII Simpósio Brasileiro de Informática na Educação, 610-619.

Flores, J. \& Becerra, M. (2002) La educación superior en entornos virtuales - el caso del programa Universidad Virtual de Quilmes. Bernal: Universidad Nacional de Quilmes.

Garcia, L. A., \& Lins, V. S. (2008) As tecnologias de Informação e Comunicação na Formação de Professores no Ensino de Ciências. Cadernos de Aplicação, 21(2).

Gil Pérez, D. \& Martinez Torregrosa, J. (1983) A model for problem-solving in accordance whith scientific methodology. European Journal of Science Education, 5(4), 477-455, 1983.

Gil PéreZ, D., Martínez-Torregrosa, J., Ramirez, L., Dumas-Carré, A, Gofard, M. \& Carvalho, A. M. P. (1992) Questionando a Didáctica de Resolução de Problemas: elaboração de um Modelo Alternativo. Caderno Catarinense de Ensino de Física, 9(1), 7-19.

Gutierrez, S. (2005) “Weblogs e Educação: Contribuição para a Construção de uma Teoria”, Novas Tecnologias na Educação, 3(1), 01-17.

Hine, C. (2005).Virtual Methods and the Sociology of CyberSocial-Scientific Knowledge. In: C. HINE (org), Virtual Methods. Issues in Social Research on the Internet. Berg.

Jesus, M. C. P. et al. (2011) Educação permanente em Enfermagem em um hospital universitário. Revista Escola Enfermagem USP (Online), 45(5), 12291236 , out.

Johnson, R. \& johnson, D. (2001) Cooperative learning and conflict resolution. New Horizons for Learning, Seattle, WA http://www.newhorizons.org/strategies/cooperative/johnson.htm. 
Leite, L. (2001) Contributos para uma utilização mais fundamentada do trabalho laboratorial noensino das Ciências. In: Caetano, H. V., Santos, M. G. (orgs.). Cadernos Didácticos de Ciências 1. Departamento do Ensino Secundário.

Linard, M.(2000) Less TIC en Education: un pont Possible entre Faire et Dire. In Les jeunes et les médias (pp. 151-177). Hachette.

López de Lara, Y. de la G. (2000) Colaboración entre iguales e aprendizage escolar. In: III Conferência De Pesquisa Sócio-Cultural, 16, 20 julho 2000 , Campinas. Anais... 1-18.

Malheiros, B. T. (2011) Metodologia da pesquisa em educação. LTC,

Maturana R., H. \& Varela Garcia, F.J. (2002). A árvore do conhecimento: as bases biológicas da compreensão humana. $2^{\mathrm{a}}$ Ed. Tradução Humberto Mariotti e Lia Diskin. Palas Athenas.

MengallI, N. M. \& Camas, N. P. V. (2013). Interface for Interaction and KnowledgeBuilding on the Web: A Look at the Educational Curriculum and the Social Network of the Systematic Learning Group. In: Gulsun Eby, T. Volkan Yuzer. (Org.). Project Management Approaches for Online Learning Design. IGI Global.

Oliveira, G. (2013). Estudo de Casos. In Costa, Oliveira e Cecy, (Orgs) Metodologias Ativas: aplicações e vivências em Educação Farmacêutica. Abenfarbio.

Pallof, R. M., \& Pratt, K. (2002) Estimulando a Aprendizagem Colaborativa. In: Construindo Comunidades de Aprendizagem no Ciberespaço: estratégias eficientes para salas de aula on-line. Artmed.

Pecotche, C. B. G. (2011). Logosofia: ciência e método. Ed. Logosófica.

Peixoto A. G., (2016) O uso de metodologias ativas como ferramenta de potencialização da aprendizagem de diagramas de caso de uso. Periódico Científico Outras Palavras, 12(2), 35-49.

Ribeiro, E. N., Mendonça, G. A. A., \& Mendonça, A. F.(2007) A importância dos ambientes virtuais de aprendizagem na busca de novos domínios da EAD. In XIII Congresso Internacional da Associação Brasileira de Educação a Distância. Curitiba.

Santos E., \& Weber A.(2013) Educação e cibercultura: aprendizagem ubíqua no currículo da disciplina didática. Revista. Diálogo Educacional., 13(38), 285303, Curitiba.

Segura E., \& Kalhil J. B.(2013) A Metodologia Ativa Como Proposta Para O Ensino De Ciências. Revista REAMEC-Rede Amazônica de Educação em Ciências e Matemática, n.03, Cuiabá - MT.

Seixas, C. A., et al.(2012) Ambiente virtual de aprendizagem: estruturação para roteiro de curso online. Revista Brasileira de Enfermagem, 65(4), 660-6.

Silva C. C. \& Kalhil J. B. (2017) A aprendizagem de genética à luz da Teoria Fundamentada: um ensaio preliminar. Ciência e. Educação, 23(1), 125-140

Soares, E. M. S., Valentini, C. B. \& Rech, J. (2017) Convivência e aprendizagem em ambientes virtuais: uma reflexão a partir da biologia do conhecer. Educação revista. 27(3).

Souza E. S. R. \& RozaL, E.F. (2016) Instrução por modelagem de David Hestenes: uma proposta de ciclo de modelagem temático e discussões sobre alfabetização científica. Amazônia - Revista de Educação em Ciências e Matemática 12 (24), 99-115.

Souza. D. R. et.al.(2016) Ensino colaborativo: benefícios e desafios. Educação, 6(3), 91-105.

Suart, R. C., \& Marcondes, M. E. (2008) Atividades Experimentais Investigativas: habilidades manifestadas por alunos do Ensino Médio. In: XIV Encontro Nacional de Ensino de Química. Atas... Universidade Federal do Paraná.

Teixeira, E., M. \& F. P. A. M., Gomes, A. S. G (2011) "Microblogging como Estilo de Interação e Colaboração em Ambientes Virtuais de Ensino e Aprendizagem”. In: XXII Simpósio Brasileiro de Informática na Educação, 956- 959.

Torres, P. L., Irala, E. A. F.(2007) Algumas vias para entretecer o pensar e o agir. Aprendizagem colaborativa. SANAR/PR.

Valente, J. A. (2005). (Org.). Computadores e conhecimento: repensando a educação. (2a ed.), Unicamp, p. 1-51.

Valverde, J. G., Llobera, J. R., Llitjós, V. A. (2005) La atención a la diversidad en las prácticas de laboratório de química: los niveles de abertura. . Revista Electrônica de Enseñanza de las Ciencias, 24 (1), 59-70. 